\title{
La caja de Pandora del catolicismo social: una historia inacabada
}

\author{
Miranda Lida
}

Conicet - Universidad de San Andrés

lidamirand@gmail.com

Title: Pandora's box of social Catholicism: an unfinished story

Resumen: El presente ensayo aborda la relación de la Iglesia Católica con las trabajadoras y los trabajadores a partir de la reflexión sobre las transformaciones y limitaciones sufridas por el catolicismo social desde sus orígenes a finales del siglo XIX hasta los albores del siglo XXI. Para ello se analiza el avance y repliegue de sus estrategias en el caso argentino a partir de distintos ejes tales como el origen y el crecimiento de los Círculos de Obreros, el impacto de las transformaciones producto de los años de entreguerras y el punto de inflexión que significó el fin de la Segunda Guerra Mundial.

Palabras clave: catolicismo social - Iglesia católica - clase trabajadora-Argentina

\begin{abstract}
This essay addresses the relationship between the Catholic Church and the working class from the transformations and limitations suffered by Social Catholicism since its origins at the end of the 19th century to the dawn of the 21 st century. For this purpose, the progress and withdrawal of its strategies in Argentina are analyzed from different axes such as the origin and growth of the Catholic Worker Circles, the impact of the transformations of the interwar period and the inflection point that meant the end of the Second World War.
\end{abstract}

Keywords: social catholicism - catholic church - working class - Argentina

Recepción: 15 de marzo de 2018. Aprobación: 28 de abril de 2018.

(Archivos, año VII, $\mathrm{n}^{\circ}$ 13, septiembre de 2018, pp. 13-31) 
En las décadas que siguieron a la Revolución Francesa y la Revolución Industrial, se volvió un lugar común asociar a la Iglesia católica con la contrarrevolución y el tradicionalismo, gracias a sus estrechos contactos, en las sociedades europeas, con las aristocracias más reaccionarias. En América Latina, a su vez, la Iglesia católica estuvo forzosamente asociada a la historia de la ocupación colonial, con sus estructuras sociales jerárquicas, propias de Antiguo Régimen. En el siglo XIX la desconfianza hacia la Iglesia católica persistió, de alli que fuera frecuente que se la considerara como un enemigo irreconciliable de las tendencias democratizadoras que apuntaban a fortalecer los derechos individuales frente a los residuos corporativistas. Las ideologias progresistas del siglo XIX, entre ellas el liberalismo y el socialismo, desconfiaron en gran medida de la Iglesia, e incluso en ocasiones se comportaron como sus enemigos acérrimos. De este modo esta quedó confinada y desprestigiada. Se la acusó de monárquica, reaccionaria y de ser un firme emblema de un Antiguo Régimen que se resistía a ser desplazado por la modernidad. Quedó en la vereda de enfrente con respecto a las luchas por la ampliación de los derechos políticos en pos de una mayor democratización frente a las tradicionales monarquías absolutas, y también quedó al margen de los reclamos de las incipientes clases obreras que clamaban por justicia social y leyes que protegieran mínimamente su calidad de vida. En efecto, su posición, al menos inicial, frente a la aparición de los movimientos obreros fue de profunda desconfianza. Cuando en la primera mitad del siglo XIX Félicité Robert de Lamennais procuró conciliar catolicismo, romanticismo, libertad y conciencia social, se topó con la dura condena papal, en un gesto que se volvió todo un signo de los tiempos.

Pero la doble revolución -industrial y democrática- demostró que había llegado para quedarse. Así, a la Iglesia católica no le quedó más opción que comenzar a limar sus asperezas. Hacia fines del siglo XIX, tenía todavía dificultades para reconciliarse con el individualismo y el sufragio universal, así como con cualquier idea de cuño democrático, pero comenzó a reconocer que la cuestión social constituía un reclamo legítimo que debía ser atendido, aunque sólo fuera por preservar el orden y evitar todavía más desbordes revolucionarios en Europa. De esta manera, además, la Iglesia católica lograría ofrecer una imagen remozada frente a una sociedad en plena transformación, que hasta entonces le había sido mayormente esquiva. Se hizo cargo, pues, de los reclamos de justicia social, que reconoció como legítimos en la encíclica Rerum Novarum (1891) del papa León XIII, un documento que se volvería programático en la Doctrina Social de la Iglesia del catolicismo del siglo XX. La Rerum Novarum, además, colocaba al Estado como árbitro adecuado entre capital y trabajo, a la par que también reconocía el derecho a la 
sindicación por parte de los trabajadores, como mecanismo legítimo para organizarse y alzar su voz frente a los sectores patronales. Fue un documento clave que en su hora fue percibido como histórico, dado que no sólo tocaba temas de enorme actualidad e impacto social, sino que además ayudaba a aggiornar la imagen de la Iglesia católica en Occidente.

Era un gesto importante, pero sin embargo se trataba de una respuesta que llegaba bastante tarde, más de un siglo después de la propia revolución industrial. Además, el socialismo llevaba décadas de desarrollo a esa altura del partido y en algunos países había logrado organizar sólidas estructuras obreras. De tal manera que el catolicismo social que se desarrollaría bajo la sombra de la encíclica Rerum Novarum se encontró disputando el terreno con el socialismo, en una batalla que tenía mucho de desigual. Ahora bien, el catolicismo social no sólo tuvo que competir con tradiciones obreras preexistentes, muchas de ellas con vasta experiencia de lucha, frente a las cuales la iniciativa católica se mostraba novel e inexperimentada, sino que, además, para peor, debió enfrentarse a las reticencias de los sectores más conservadores dentro del propio catolicismo, que veían a estos grupos de católicos sociales como "peligrosos" o "rojos". Los sectores católicos más tradicionales, muchos de ellos pertenecientes a círculos otrora aristocráticos, veían a sus principales exponentes como amenazadores, como puede verse a través de la vasta reacción que suscitó en Francia el movimiento conocido como Le Sillon, cuyo principal referente fue Marc Sangnier, cuando a comienzos del siglo XX se acercó a barriadas obreras y recibió como recompensa la condena episcopal. Los ejemplos de este tenor pueden multiplicarse: las asociaciones católicas de perfil obrero (aunque sólo fuera por su discurso) que comenzaron a conformarse en diferentes regiones de Europa occidental y América Latina despertaron reticencia en los sectores más conservadores del catolicismo, una desconfianza que parecía destinada a perdurar.

En la Argentina, la cuestión no fue menos difícil de zanjar. La incorporación de la agenda social en el catolicismo universal se producía a través del impulso llegado desde la Santa Sede. Si bien es cierto que existieron iniciativas socialcristianas locales que precedieron a la encíclica Rerum Novarum, lo cierto es que el catolicismo argentino de fines del siglo XIX no parecía muy permeable, en general, a esta cuestión. En parte porque habia cuestiones más urgentes en la agenda, como por ejemplo la necesidad de adaptarse a la nueva realidad de las leyes laicas introducidas en la década de 1880 (matrimonio civil, educación laica, registro estatal), en parte también porque quienes encabezaban el movimiento católico y de alguna manera llevaban su agenda eran un neto exponente de un catolicismo de caballeros de tipo notabiliar, tal 
como podía advertirse a través de su pertenencia a círculos más bien elitistas, poco permeables a la situación social de trabajadores, campesinos criollos o indígenas, inmigrantes pobres o desempleados. Sea como fuere, pues, la introducción del catolicismo social en la Argentina se produjo con altibajos, de ahí la dispar presencia de las asociaciones dedicadas a atender las demandas sociales de los trabajadores católicos en todo el territorio. No se aceptaba fácilmente la propia existencia de asociaciones que parecian portadoras de un carácter obrerista, de ahí que se reclamara una fuerte tutela por parte de los sectores patronales en las nuevas organizaciones católicas. Y eso al precio de dejar de lado el hecho de que la Rerum Novarum tenía un marcado sesgo eurocéntrico, puesto que era propia de países consolidados en su industrialización y no era fácil de adaptar a realidades sociales marcadas todavía por el predominio del mundo rural como sucedía en América Latina.

A lo largo del siglo XX, sin embargo, la modernización social, la expansión de los derechos tanto individuales como colectivos, el creciente protagonismo de la mujer, de los jóvenes, de las clases medias y de los propios obreros, si bien por supuesto con variaciones en función de la coyuntura política de la hora, modificó las cosas y obligó a abordar la cuestión social con enfoques renovados. Desde la Primera Guerra Mundial, de hecho, se percibieron tensiones que recorrieron el catolicismo social en la medida en que, en la Argentina, la sociedad se complejizaba y las transformaciones de la economia hacian sentir su impacto, situación que se agravó, en especial, luego de la crisis de 1929. En este contexto, el catolicismo social verificó un proceso de renovación y, al mismo tiempo, de creciente legitimación dentro de las propias jerarquías católicas que, sin embargo, no se habían mostrado hasta alli mayormente proclives a alentar movimientos católicos de composición obrera. Claro que de todas formas continuó habiendo reticencias, así como también temores a cualquier tipo de plebeyización que pudiera producirse en el catolicismo argentino. Sin embargo, ya no se podia ir contra la corriente en una época en la que incluso la Iglesia católica alentaba la expresión de las masas en sus principales festividades religiosas del siglo XX, a saber, los congresos eucarísticos. Abrir la caja de Pandora del catolicismo de masas tenía un alto precio para un movimiento como el católico que, en la Argentina en particular, había tejido durante la belle époque estrechos vínculos con las aristocracias terratenientes y a duras penas había salido del cascarón notabiliar.

Este artículo -en clave de ensayo- se organiza del siguiente modo: en primer lugar, se analizan algunos momentos clave en la historia de los Círculos de Obreros fundados por Federico Grote a través de los cuales se pueden advertir los conflictos que debió sortear el primer catolicismo social. Luego, se analizan las transformaciones que atravesó el catoli- 
cismo social en el período de entreguerras cuando procuró adaptarse a los desafios proporcionados por los cambios en la estructura social y fue capaz de dar lugar a algunas respuestas novedosas: así, por ejemplo, la incorporación de la mujer, hasta entonces bastante marginal, o de los jóvenes, e incluso la misma necesidad de reconocer una mayor autonomía de los obreros en la representación de sus intereses. Por último, y a modo de conclusión abierta, se sugieren las limitaciones del catolicismo social frente a la complejización de las demandas y los derechos sociales en el siglo XX a pesar de los vastos esfuerzos que hizo la propia Iglesia por aggiornar su mirada acerca del problema, desde el papa León XIII hasta Francisco.

\section{Círculos de Obreros: alcances y limitaciones}

Ya sea que se los considere una respuesta defensiva ante el avance socialista, anarquista o comunista; ya sea que se les reconozca una significación que va más allá de ser una reacción al "temor rojo", los Círculos de Obreros constituyen un tema bastante transitado en la historiografia (Auza, 1987; Vidal, 2006, entre otros trabajos). Ahora bien, no debe confundirse a los Círculos de Obreros con sindicatos, dado que no defendian intereses sectoriales organizados en torno de un oficio o lugar de trabajo, sino que se organizaban como cualquier otra organización del laicado católico a partir de la célula básica compuesta por la parroquia. El hecho de que se establecieran por parroquia, es decir por barrio, favoreció su aspecto no clasista dado que estaban abiertos a todos los hombres del barrio, sin importar su actividad laboral -las mujeres no fueron incluidas como beneficiarias de la asociación, ni siquiera las trabajadoras domésticas, a las que se intentó llegar poco y mal-. Tan sólo en los barrios de composición obrera marcadamente homogénea los Círculos de Obreros llegaron a adquirir una connotación clasista-así el caso de la barriada de Avellaneda, donde el catolicismo social desplegó una amplia labor, encabezada por el cura lugareño Bartolomé Ayrolo hacia 1900-. Pero en general esto era más la excepción que la regla, en especial en la ciudad de Buenos Aires. Así, la composición social de los Círculos fue desde un comienzo interclasista, rasgo que habrá de procurar mantenerse a lo largo del tiempo. Abogados y otros profesionales compusieron el núcleo fundador del primer círculo, como es el caso del doctor Santiago O'Farrell, que llegó a ocupar una banca en la Cámara de Diputados, en 1904, en la misma elección por circunscripciones uninominales que le daría un escaño al socialista Alfredo Palacios.

Un reglamento de los Círculos de 1896 distinguía tres categorías de socios, jerárquicamente considerados: honorarios (los notables de la asociación), protectores (que oficiaban de mecenas y colaboraban 
generosamente) y activos (los verdaderos cotizantes, pero con módicas cuotas). Los ingresos obtenidos se destinaban a varios fines: realizar actos festivos, con conferencias y otras actividades, para los socios y sus familias (a ellos sí podian acompañar las mujeres); socorro mutuo en caso de enfermedad, con servicios de farmacia (en principio, los servicios prestados eran bastante rudimentarios, pero con el correr del tiempo, se complejizaron, en consonancia con los progresos habidos en la salud pública); gastos de entierro y funerales, para lo cual se erigiría un panteón; fundación de escuelas, en especial para adultos (hubo mujeres de elite que apadrinaron estas iniciativas); cajas de ahorro; bandas de música y agencias de colocaciones para desempleados. ${ }^{1}$ Contemplaron también proyectos para atender el problema de la vivienda obrera. Por su composición interclasista y por las funciones que atendia, pues, los Círculos se parecían más a una mutual -similar a tantas otras que existían en Buenos Aires para la misma época, comenzando por las que establecieron las distintas comunidades de inmigrantes- que a un sindicato obrero.

De hecho, en los Círculos existian fuertes reticencias a aceptar la idea de formar sindicatos católicos, y más si estos adoptaban un perfil obrerista, puesto que se temía que se los confundiera con sociedades "de resistencia", y que no gozaran de la respetabilidad que los notables esperaban de una organización "obrera", pero católica. Más contundente era todavía su desconfianza hacia cualquier medida de fuerza. Estas reticencias hacian pasar a los Círculos por puramente amarillistas, en especial en la prensa socialista. En más de un sentido lo eran, pero está claro que los Círculos tampoco se agotaban en ello. Jugaron un papel muy activo en la promoción de legislación obrera, para lo cual elevaron un sinnúmero de petitorios al Congreso en pos de normas que limitaran la extensión de la jornada laboral, el trabajo de mujeres y niños, el descanso dominical, entre otros items. Optaban por la vía legal y negociada, antes que cualquier medida de fuerza en la que evitaban recaer a toda costa. El desarrollo de ideas reformistas en la elite del 900 ayudó a que la postura socialcristiana encontrara eco en los primeros años del siglo (Zimmermann, 1995). Pero, claro está, ello se produjo al precio de ganarse muchos enemigos. Los Círculos fueron acusados de ser los bufones de los patrones, una acusación que ponía en jaque mucho de su legitimidad: no pudo ser ignorada por sus voceros e intelectuales más lúcidos (Martín, 2012; Rapalo, 2012). Tanto es así que llegaron a tender lazos con el Jockey Club, que se comprometió a apadrinar algunas de

1. Reglamento de los Círculos de Obreros de la República Argentina, Buenos Aires, Tipografia Salesiana del Colegio Pío IX, 1896. 
sus iniciativas. ${ }^{2}$ No ha de extrañar, pues, encontrar en Caras y Caretas las noticias de los diferentes eventos organizados por los Círculos de Capital: promenades-concerts, conferencias, actos sociales. Claro que desde otra óptica a esto mismo se lo denunciaba como paternalismo. La fuerte presencia que las elites sociales y políticas tenian en los cargos directivos de los Círculos no dejaron de provocar tensiones: había quejas recurrentes porque los obreros ocupaban sitios incómodos en las asambleas, mientras que se reservaban los mejores a los doctores de las comisiones directivas. ${ }^{3}$ Por muchas razones los Círculos se toparon con dificultades. En Buenos Aires, tan sólo las parroquias de la Concepción, Belgrano, Santa Lucía, San Cristóbal, Balvanera, Palermo y Flores habían constituido su respectiva sede para 1905, a la que debe sumársele el Círculo Central -llevaba este nombre la primera fundación, que databa de 1892 y que en 1907 se mudaría a Junín 1063, una sede austera pero elegante, costeada en buena medida por la señora Elortondo de Ocampo-. En el interior, su presencia se concentró en las ciudades de mayor peso, en especial, capitales de provincia, pero no fue más allá: rara vez alcanzó ámbitos rurales, si bien en Tucumán se conformaron algunos círculos en los ingenios azucareros (Roselli, 2009). La distribución a lo largo del país fue desigual. Para su legitimación se recurrió a las autoridades eclesiásticas, que le prestaron su apoyo, incluso muchas veces con la presencia de los sucesivos nuncios. Sobre estas bases, procuraron presentarse como una asociación católica de alcance nacional, la primera de este tipo que celebraba congresos regulares, tenía estatutos propios y se extendia por todo el país.

Sin embargo, fueron insuficientes para integrar y nacionalizar el catolicismo argentino. Éste se hallaba atravesado por varias líneas de falla que impedian su reducción a la unidad. Por un lado, cuenta el hecho de que los Círculos de Obreros integraran poco y mal a las mujeres. Grote fundó los Círculos como una asociación eminentemente masculina, en la que las mujeres tan sólo podían participar en sus actividades sociales, no así en las demás. Siquiera estaban autorizadas a asistir a las peregrinaciones que los Círculos organizaban anualmente en Luján: "solo hombres", se publicaba a modo de advertencia en la prensa católica. Tan sólo cuando Miguel De Andrea comenzó a oficiar de secretario del Círculo Central, en 1902, comenzó a abrirles muy lentamente las puertas a las mujeres. Pero ya era tarde para intentar borrar la impronta masculina que Grote les dio a los Círculos de Obreros. Claro que la distinción según género no debería sorprender, puesto que era sumamente frecuente en la época, y más en ámbitos católicos, por tradición conservadores en

2. "En pro de los obreros", La Voz de la Iglesia, 19 de septiembre de 1905.

3. Un ejemplo: El Pueblo, 15 de septiembre de 1907. 
cuestiones de género. Los clubes católicos de caballeros y sus cofradias, los sucesivos ensayos de conformar un partido político católico -un terreno eminentemente masculino, en la época-, las conferencias y peregrinaciones sólo para hombres, etc., dan cuenta de la existencia de un catolicismo masculino dificilmente integrado que se maneja con sus propios códigos, algunos más caballerescos, más burgueses, otros más plebeyos. Esto no significa que, de tanto acercarse a las elites, los Círculos se apartaran de la acción social entre los sectores populares. Se preocuparon por el alza en los precios de los productos básicos que consumian las familias más humildes y fomentaron el cooperativismo, a fin de poder proporcionar precios más ventajosos que los que ofrecian las tiendas comerciales. El cooperativismo se hallaba en franca expansión, tal como puso en evidencia en 1911 la fundación del Museo Social Argentino, que abogaría por un abandono del liberalismo doctrinario, en pos de introducir moderadas reformas e iniciativas inspiradas en el colectivismo y el mutualismo (Zimmermann, 1995: 74-78). En neta sintonía con estas tendencias -los lazos entre el Museo Social y el catolicismo fueron muy estrechos-, los Círculos de Obreros fundaron en 1912 "La Cooperación", una cooperativa que ofrecería alimentos con descuentos de al menos un diez por ciento. Siempre con sesgo reformista, alentaron la legislación social en torno de diferentes temáticas: fijación de la jornada laboral, respeto por el descanso dominical (un reclamo de larga data, ya fuere con argumentos teológicos o higiénicos, puesto que en este punto ambos se solapaban sin provocar estridencias), protección al trabajo de niños y mujeres, jubilaciones, seguros de enfermedad y accidente, vivienda y establecimiento de agencias de colocaciones reconocidas por el Estado. ${ }^{4}$ El arribo de Arturo Bas y Juan F. Cafferata a la Cámara de Diputados en 1912 permitió que muchas de estas demandas encontraran eficaces tribunos parlamentarios; la labor de los diputados cordobeses del Partido Constitucional (católico) guardó estrecha relación con los reclamos de los Círculos de Obreros en más de un sentido. ${ }^{5}$

Por otro lado, en 1912, la llegada a los puestos directivos de los Círculos de monseñor Miguel De Andrea como director espiritual, y de Alejandro Bunge, que quedará a cargo de la Junta de Gobierno de la institución, no puede ser minimizada, puesto que Bunge era colaborador del Departamento Nacional de Trabajo (DNT). Las nuevas autoridades, que dieron lugar a recelos por parte de quienes hubieran preferido la

4. "Legislación obrera. Proyectos de ley que esperan la sanción de la Cámara", El Trabajo, agosto de 1913, pp. 1-2.

5. Acción parlamentaria del Dr. Arturo M. Bas, diputado nacional por Córdoba (19121916), Buenos Aires: Talleres Rosso, 1915. 
continuidad de Grote, su fundador, en lugar del joven De Andrea, a quien se acusaba de dar prioridad a sus contactos entre las clases altas, debieron atajarse de las críticas que rondaban la institución. No ignoraban las acusaciones de ser amarillistas y de estar atados al paternalismo de los patrones. Contra ello, Bunge propuso que los propios obreros tuvieran participación a nivel directivo en los Círculos de Obreros, y que los altos cargos no quedaran confinados en manos de los notables, como había ocurrido hasta ahi. ${ }^{6}$ Los nuevos dirigentes alentaron también la formación de "verdaderos" sindicatos según se decía, algo que durante la gestión de Grote había provocado áridas discusiones. Desde 1912 se proyectó establecer una federación sindical asociada a los Círculos, que recién sería fundada en 1917 bajo el nombre de la Federación Profesional Argentina (FPA). En ella prevaleció un tono conservador, como era de esperar: la aceptación de los sindicatos como vía válida para los reclamos de las clases trabajadoras conviviria con la condena hacia la huelga, en tanto que medida de fuerza gremial. Como dijera el propio De Andrea, años después, se trataba ante todo de armonizar capital y trabajo: "les hablábamos de deberes más que de derechos" (De Andrea, 1945: 163-164).

Bajo la dirección de De Andrea, se afianzó la difusión de valores patrióticos en los Círculos de Obreros. Este sesgo no era nuevo -el canto del Himno Nacional estaba integrado a sus actividades-, pero De Andrea se encargó de recalcar la necesidad de izar la bandera en las fiestas cívicas y ofrecer conferencias de contenido patriótico. Era la asociación católica que se encontraba mejor preparada para difundir valores patrióticos y nacionalistas, gracias a su composición interclasista, a la vez que cosmopolita: puesto que no estaban atados a ninguna identidad étnica, regional o de clase, podian colocar por encima la bandera argentina. No debería sorprender en este contexto de fuerte impulso nacionalista que una institución como los Círculos de Obreros viera con malos ojos el crecimiento de la inmigración y sugiriera la necesidad de establecer trabas legales al ingreso de extranjeros, puesto que los consideraban causa directa del aumento de la desocupación: el boletín El Trabajo no vaciló en privilegiar la mano de obra nacional en desmedro de los extranjeros, que antes de la Primera Guerra Mundial llegaron al país masivamente. ${ }^{7}$ La relación de los Círculos de Obreros con las mutuales

6. "Círculos de Obreros. Discurso del Ingeniero Alejandro Bunge", El Trabajo, septiembre de 1913, pp. 5-7. Las tensiones entre los notables en las organizaciones católicas y las presiones democratizadoras también se observan en el Partido Constitucional. Véase Castro (2013) y Lida (2013).

7. "Para la mejor organización del mercado de trabajo", El Trabajo, julio de 1913, pp. 1-2. 
de inmigrantes, frente a la presión de los extranjeros para integrarse al mercado laboral, no fue, pues, fluida. Los Círculos no desatendieron la necesidad de integrar a los inmigrantes católicos, en especial, a los italianos, de ahí que (durante la gestión de De Andrea, una vez más) comenzaron a ofrecerles agencias de colocaciones en su propio idioma para facilitarles la búsqueda de empleo, pero la iniciativa no tardó en despertar suspicacias en las mutuales italianas, que vieron esto como una amenazadora competencia. ${ }^{8}$ Era un primer intento, si bien tardío, de atender a los inmigrantes por parte de una organización mutual de valores nacionalistas como fueron los Círculos de Obreros que, así, pusieron en evidencia algunas de sus limitaciones. Otra novedad que trajo consigo la nueva gestión fue la intención de interpelar mejor a las mujeres, con quienes De Andrea tendió estrechos lazos desde comienzos de siglo, pero sin que se les reconociera lugar alguno en los Círculos. Ahora bien, la incorporación de Celia Lapalma de Emery, una figura destacada de la labor socialcristiana femenina, como colaboradora estable en el boletín de los Círculos, no es un dato insignificante. Lo mismo cabe decir de la colaboración que le prestaron a la Caja Dotal de Obreras, una iniciativa de María Unzué de Alvear para promover el ahorro y las "sanas" costumbres entre las trabajadoras. Aún con todas sus limitaciones, la agenda de las décadas subsiguientes quedó trazada durante la década del Centenario: darles a los obreros más participación en los puestos directivos, así como también reconocer las necesidades específicas de los recién llegados al mercado de trabajo, sean inmigrantes o incluso los jóvenes, de la misma manera que las de las mujeres fueron los principales desafios de los años de entreguerras.

\section{Se abre la caja de Pandora. Las transformaciones de entreguerras}

Las transformaciones sucedidas en el seno de los Círculos de Obreros en las primeras décadas del siglo XX son sintomáticas de lo que a más vasta escala se estaba produciendo a su vez en el catolicismo todo. Un proceso a través del cual una asociación de varones, que se conformó en estrecha vinculación con las elites socioeconómicas del país, terminó democratizándose contra su pesar en su funcionamiento interno, lo cual abrió el paso a que en las cúpulas directivas se integraran personas provenientes de una extracción social propiamente obrera. Se trata de obreros y afiliados que atravesaron el proceso de integración a una mutual de carácter interclasista, que a su vez se caracterizó, también, por recalcar y transmitir valores nacionalistas a través de sus rituales,

8. "Contra los Círculos de Obreros", El Trabajo, enero de 1913, p. 5; "Los Círculos en Roma”, El Trabajo, marzo de 1913, pp. 1-3. 
movilizaciones y otras expresiones de pedagogia cívica. Y naturalmente, estas transformaciones se hicieron visibles, también, en la fisonomía de las peregrinaciones y movilizaciones públicas de esta organización católica: si hasta los años de la Primera Guerra Mundial los Círculos solían sacar a la calle sus figuras más conspicuas, compuestas por caballeros ataviados de galera y guantes, muy cercanos a las élites sociales y políticas, con el correr de los años, y en especial luego de la Ley Sáenz Peña y la democratización que le sucedió, las columnas se volvieron menos solemnes, más plebeyas, incluso más recias. Así, pues, una organización que en el catolicismo del 900 había sido clave para sacar el catolicismo a la calle en compactas columnas quedó trastocada vis-à-vis las transformaciones sociales de entreguerras, que dieron lugar a una dinámica de movilización social y política propia de los más modernos centros urbanos (Lida, 2016: 15-38).

En este contexto, se dieron una serie de cambios estructurales que apuntarian a transformar de raíz el perfil tradicionalmente paternalista de los Círculos de Obreros. La reestructuración interna, que había recibido sus primeros impulsos en 1912, se afianzó luego de 1917 una vez que los Círculos se lanzaron a la conformación de los primeros sindicatos, que se nuclearian en la Federación Profesional Argentina. (Puesto que los Círculos desde sus origenes habían sido remisos a organizar sindicalmente a los trabajadores, la iniciativa tardó mucho en arraigar; de todas maneras es necesario reconocer que en el seno de la FPA era toda una innovación que se propusiera instaurar la representación obrera por rama de actividad, como si se tratara de "gremios de verdad" [sic], según se dijo en la reunión inaugural de esta nueva entidad gremial católica.) $)^{9}$ No es de extrañar que en las movilizaciones de los Círculos de Obreros adquirieran creciente centralidad a partir de aquí los reclamos sindicales y laborales: jubilaciones para trabajadores (ferroviarios, gasistas, entre otros), leyes que regularan el funcionamiento de las agencias de colocaciones, la plena vigencia de la ley de Casas Baratas que habia sido impulsada por Bas y Caferatta, el reclamo de restringir la exportación de alimentos a fin de que no se encarecieran los precios en el mercado interno, entre distintas demandas de contenido social que enarbolarian a partir de $1916 .{ }^{10}$ Pero sin duda el cambio más significativo fue el que se verificó en la composición de la propia asociación católica, puesto que -finalmente- se admitió por primera vez el reclutamiento de obreros para los cargos directivos de la asociación. Ello hizo posible que el obrero

9. “Federación Profesional Argentina”, El Pueblo, 2 de agosto de 1917, p. 1; El Pueblo, 12 de mayo de 1917.

10. El Pueblo, 18 de noviembre de 1916; El Pueblo, 17 de mayo de 1917, entre otros ejemplos. 
gráfico Carlos Conci -fue, además, propagandista socialcristiano de tono radicalizado- fuera designado en 1920 jefe de la Junta de Gobierno de los Círculos de Obreros: por primera vez los Círculos pasaron a estar dirigidos por figuras provenientes de la clase obrera, lo cual ayudaria, se supone, a barrer con el carácter paternalista al que habian estado atados desde su fundación. Se habló, de hecho, de una depuración en el seno de la propia institución porque -según ahora se admitía- los Círculos habían sido netamente "conservadores" en sus orígenes. ${ }^{11}$ (No debe leerse esto, sin embargo, como un corrimiento de los Círculos hacia la izquierda, puesto que adhirieron sin vacilar a la Internacional Blanca, conformada por partidos conservadores y cristianos en Europa en la primera posguerra, con el neto propósito de contrapesar el influjo de la revolución soviética. ${ }^{12}$ En este sentido, no es casual que los Círculos encabezaran una colecta por la Rusia "martirizada por los bolcheviques", en el transcurso de 1930. El cambio solamente involucró a la composición social de los dirigentes, que ahora tendrían un perfil menos elitista.)

Ello repercutió en el estilo de las movilizaciones que los Círculos realizarian en el espacio público a partir de esta fecha. Un dato elocuente fue que, a partir de 1921, y por iniciativa de Carlos Conci, los Círculos comenzaron a celebrar en las calles, con movilizaciones públicas, el 1 de mayo, en un neto afán por arrebatarle a las izquierdas la celebración de esta fecha. La movilización iba acompañada además de petitorios que entregarian al Congreso Nacional donde se reclamaba, en nombre de la justicia social, leyes que regularan la jornada de trabajo y los salarios, además del descanso dominical porque, se argüía, las disposiciones vigentes rara vez se cumplían en la práctica. La convocatoria para el 1 de mayo tuvo altibajos a lo largo de los años 20, pero de todos modos los Círculos procuraron alcanzar una cierta presencia en las calles, con oradores de barricada como el aguerrido sacerdote Dionisio Napal y el joven Virgilio Filippo, acompañados de consignas militantes, simbolos nacionales y toda la parafernalia de la incipiente politica de masas, que incluía banderas, tribunas, oradores previamente designados, etc. Entre las consignas que se utilizaban para movilizar las filas se contaban "Dar por Cristo la cara", "Proletarios del mundo, uníos en Cristo", entre otras, que apelaban al carácter obrero y masculino de sus participantes. $\mathrm{El}$ hecho de que desde 1920 las autoridades de los Círculos estuvieran conformadas por personas de origen social propiamente obrero reforzó su carácter viril, puesto que no estaba en manos de caballeros aburguesados, como antaño, sino de trabajadores que podían ofrecer una

11. El Pueblo, 5 de agosto de 1923.

12. La Obra de los Círculos de Obreros. Características. Organización. Programa, Buenos Aires, Junta de Gobierno, 1925. 
imagen de mayor reciedumbre. En los años sucesivos, no tardaremos en encontrarnos con el lamento de Leonardo Castellani por la excesiva feminización del catolicismo, al precio de poner en jaque su virilidad, un lamento que calzaba bien con el aire que se respiraba en una tradicional asociación masculina como los Círculos de Obreros (Caimari, 2005). En este sentido, véase un aviso por el cual los Círculos invitaban a asistir a una de sus habituales movilizaciones, que no iba dirigida a sus socios pura y exclusivamente, sino a todos los varones católicos:

¿Es Ud. hombre de pelo en pecho? ¿Capaz de enrostrar a sus adversarios que le escarnecen y que se burlan por su piedad, por su fe y por su doctrina? Forme en las filas de los Círculos de Obreros. [...] Ud. y sus amigos no deben faltar a esta cita de honor. Que nadie falte. ${ }^{13}$

Si estas eran algunas de las consignas a las que apelaban para movilizar sus filas, está claro que la apropiación del 1 de mayo como fecha de alto valor simbólico para la movilización obrera católica no podría despojarse de su aspecto militante y combativo. Sin embargo, al mismo tiempo los Círculos también procuraban darle respetabilidad a una fecha clave para la movilización obrera que en el pasado había estado asociada a la violencia, imagen que ahora se quería dejar atrás, gracias a la incorporación de valores y símbolos nacionales en el festejo obrero católico. "Por todo ello, los Círculos de Obreros han visto con agrado la generalización de la Fiesta del Trabajo y han aplaudido el acto por el cual los poderes del Estado [...] la han aceptado y reconocido oficialmente". ${ }^{14}$ Una sucinta explicación del sentido de estas movilizaciones aclaraba que:

A medida que se cristianizaba, la fecha [1 de mayo] iba perdiendo su característica netamente revolucionaria, para ser aceptada sin reservas por los obreros que tienen inscriptos en su programa los principios de la democracia cristiana [...]

Fue así que se preparó una movilización y desfile por la vía pública, previas conferencias y concentraciones, finalizando con una exteriorización de fuerzas en la Plaza del Congreso que se levantaron dos tribunas para los oradores. Era la primera vez en la Argentina y seguramente en América que en el día 1 de mayo masas obreras desfilaban por las calles precedidas por la bandera nacional y que, una vez concentradas, dejaron oír con voces marciales y viriles la canción patria. [...] De los

13. "Aviso", El Pueblo, 29 de marzo de 1923.

14. "Los Círculos de Obreros y su concepto del 1 de mayo. Un manifiesto público", El Pueblo, 29 de abril de 1926. 
balcones y aceras partieron abundantes los aplausos y las flores, estas últimas arrojadas por manos femeninas. ${ }^{15}$

Si el intento de hacer suya la fiesta obrera llevaria a que en los Círculos recrudeciera en la década de 1920 tanto la movilización de masas como la retórica militante, con especial éxito entre los sectores más jóvenes del movimiento socialcristiano (no es casual que en 1930 los Círculos de Obreros se lanzaran a proyectar la fundación de su rama juvenil, que más tarde sería establecida con el nombre de Vanguardias Obreras Católicas), de todas formas ello no sería suficiente para darle a los Círculos de Obreros un papel protagónico en el catolicismo de masas propio de la década de 1930. Cabe aventurar que su carácter netamente masculino fue un fuerte obstáculo en este sentido. En la década de 1920, las mujeres católicas ganaron intenso protagonismo en la movilización callejera (ya fuere la rama femenina de la Unión Popular Católica Argentina, la Federación de Asociaciones Católicas de Empleadas impulsada por Monseñor de Andrea, entre otras asociaciones católicas que le confirieron a la mujer un lugar protagónico, incluso en puestos directivos, y, más tarde, en la década de 1930, en la Acción Católica Argentina, cuya rama femenina fue muy influyente en las jerarquías eclesiásticas), pero los Círculos se mostraron igual de remisos que antaño a acogerlas en su seno. El protagonismo femenino de muchas de las columnas que asistieron al Congreso Eucarístico Internacional de 1934, como se advirtió en las fotos del evento, donde abundaban las mujeres cubiertas con mantilla, eran todo un desafio para las organizaciones de varones: de hecho, en el marco del Congreso, los hombres tan sólo conservaron un espacio propio y exclusivo en la procesión y comunión nocturna que se celebró en una de las veladas más recordadas de aquel evento.

Pero quizás el desafio más prominente fue el que provino de los jóvenes obreros, en especial a partir de la década de 1930. La incorporación de la juventud como un colectivo específico cuyas demandas requerian en el seno de los movimientos católicos asociaciones especializadas fueron por primera vez reconocidas de manera oficial en 1919, un año después de la Reforma Universitaria, cuando se estableció la rama juvenil de la UPCA, Unión Popular Católica Argentina, una estrategia de la Iglesia para llevar adelante, desde arriba, un proceso de centralización por sobre las innumerables -si bien dispersas y desarticuladas- organizaciones del laicado. Fue entonces que se estableció la Liga Argentina de la Juventud Católica, de varones solamente, una de las ramas más innovadoras y mayo de 1930. 
originales de la UPCA, que organizaba viajes, campamentos, actividades deportivas y recreativas para jóvenes. ${ }^{16}$ La UPCA fracasó en su intento de aglutinar al laicado argentino y desembocaría en la década de 1930 en la creación de las ramas juveniles de la Acción Católica Argentina, que incluyó como novedad la incorporación activa de las mujeres, jóvenes y adultas. No obstante ello, el activismo juvenil cristiano no se detuvo; en los años 20 fue novedosa, por ejemplo, la creación de una asociación laica de mujeres jóvenes como Noel y, por otro lado, en especial, la creación de una rama juvenil en el seno de los Círculos de Obreros, bajo el nombre de Vanguardias Obreras Cristianas (VOC) (Lida, 2015).

La decisión de las autoridades de los Círculos de Obreros de abrir esta nueva rama se tomó en 1930, en coincidencia con la celebración de la primera Semana Mariana de la Juventud -gesto a favor de los jóvenes por parte del episcopado-. Todavia en 1938 la rama juvenil era un proyecto, pero a partir de ese año, y a la par de un complejo proceso de burocratización emprendido luego de la inauguración de su sanatorio en 1937, los Círculos apostaron a tentar a los jóvenes -hijos de obreros, aprendices o aspirantes- a través de diversas estrategias: la formación profesional y el adoctrinamiento ideológico, por supuesto, pero además la promesa de que la sola pertenencia a una asociación católica podría proporcionarles alguna ventaja a la hora de salir a buscar empleo. Además, se le dio impulso a la creación de una red de ateneos deportivos en Villa Devoto, zona norte del Gran Buenos Aires y otros barrios, que tenían buenas instalaciones, incluso con piscinas de natación, así como también se promovió la organización de campamentos recreativos. La rama juvenil se mostró pronto sumamente dinámica; el ejemplo de Joseph Cardijn, fundador de la Juventud Obrera Católica en Bélgica, que luego se expandiria a otros países, fue sumamente influyente. Cardijn alentaba la creación de organizaciones con líderes extraídos de las propias filas obreras. El perfil obrerista de la organización fundada por Cardijn despertó en Europa recelos y sospechas en la década de 1930: no faltaron las acusaciones de "cristianos rojos", en especial durante el apogeo de los Frentes Populares. En la Argentina, sin embargo, las VOC creadas a instancias de los Círculos se apartaron del ejemplo de Cardijn a poco de andar, tanto es así que, en 1940, terminaron por conformarse dos entidades diferentes, las VOC, en el seno de los Círculos, y la Juventud Obrera Católica (JOC), ajena a los Círculos de Obreros, apadrinada directamente por el sacerdote belga.

La rama juvenil de los Círculos, en expansión gracias a la variada oferta de actividades que podía ofrecer a través de su red de ateneos

16. "Liga Argentina de la Juventud Católica. Partida del primer contingente de acampantes", El Pueblo, 6 de enero de 1923. 
deportivos, tuvo además fuerte presencia en las calles. Los Círculos habian incorporado a su calendario la movilización del día del trabajo, que celebraban ya fuera el tradicional 1 de mayo, o bien el 15 de este mismo mes (puesto que se cumplía el aniversario de la encíclica Rerum Novarum). Ahora bien, las columnas callejeras estaban compuestas mayormente por los jóvenes, quienes ocuparon el espacio público con pancartas y reclamos obreros. El activismo juvenil, más intenso que en las ramas adultas, hizo posible que en 1942 las VOC elevaran un petitorio dirigido al Congreso nacional a fin de solicitar la sanción de una ley sobre trabajo juvenil y formación profesional, cuyo anteproyecto se encargaron también de redactar. ${ }^{17}$ Fueron recibidos por José Luis Cantilo, presidente de la Cámara de Diputados en ese momento y hombre cercano al movimiento socialcristiano. Y en marzo de 1943, los recibió el presidente Ramón Castillo, entre promesas de creación de escuelas de artes y oficios y otras iniciativas para los jóvenes. Al igual que las ramas de adultos de los Círculos de Obreros, las Vanguardias se movieron en las calles, así como también lo hicieron cerca del poder, en consonancia con las ramas de adultos de los Círculos, menos impetuosas en las calles tal vez, pero más diestras en sus gestiones políticas: se vincularon con sucesivos gobiernos de turno, interpelaron directamente a los presidentes de la "década infame" -en especial, Roberto Ortiz y Castillo, su sucesor, aunque también tuvieron trato regular años antes con Agustín P. Justo-, presentaron petitorios, respaldaron proyectos de leyes o solicitaron su sanción. ${ }^{18} \mathrm{El}$ importante número de proyectos de ley sobre temas sociales y laborales que se debatieron en el Congreso desde fines de los años 30 les ofreció un terreno apto para este tipo de intervenciones -también la Acción Católica se sumó a ello y en 1941 elevó al Congreso sus propios proyectos de ley-.$^{19}$ Los vínculos con el poder no deberían sorprender puesto que históricamente los Círculos de Obreros se caracterizaron por cultivar valores tradicionales, tales como orden y disciplina, así como también las buenas costumbres. Pero en la década de 1940 la incorporación de obreros vestidos con mamelucos en los afiches de las VOC y la JOC marcaria un matiz importante: con ese gesto, se heroificaba al obrero, recio, viril, enérgico. Un mismo carácter debían tener sus cantos populares, atractivos, vibrantes. La juventud obrera católica estuvo, así, mejor preparada que las ramas adultas del

17. "Vanguardistas en la Cámara de Diputados", Lábaro, septiembre de 1942, p. 2 del suplemento juvenil.

18. "Nota elevada a la Comisión de Legislación del Trabajo de la Cámara de Diputados", Lábaro, julio de 1942, p. 3.

19. Proyecto de ley de asignaciones familiares presentado al Congreso Nacional por la Junta Central de la Acción Católica Argentina, Buenos Aires: ACA, 1941. 
movimiento socialcristiano para recibir el peronismo; la JOC de Cardijn fue de hecho su aliada política y el sacerdote belga se entrevistó con Perón en reiteradas oportunidades. ${ }^{20}$

\section{Epílogo}

A pesar de su resistencia inicial a la sola idea de conformar movimientos obreros católicos, el catolicismo social fue transformándose a lo largo del siglo XX, unas veces a la par de los propios cambios sociales, otras, en cambio, a la zaga, sólo una vez que se hizo evidente la constatación de que dichas transformaciones serian irreversibles, mal que les pese. En medio siglo, hemos visto que el catolicismo social argentino debió aceptar como un dato inexorable que los propios obreros tenían derecho a dirigir y decidir sus destinos en sus propias organizaciones socialcristianas, salir a la calle en fechas clave del calendario obrero, incorporar de una manera u otra a las mujeres a sus propias organizaciones, dar cobijo a los inmigrantes y defender sus reivindicaciones frente a los poderes públicos y conformar organizaciones específicas que atendieran las demandas de los jóvenes obreros que acababan de ingresar (o aspiraban a hacerlo) al mercado laboral. Para la década de 1940 , la bandera de la justicia social habia ingresado plenamente a las reivindicaciones católicas, incluso aquellas avaladas directamente por la jerarquía eclesiástica, en un gesto que rompía de cuajo con el pasado señorial y paternalista de las primeras organizaciones socialcristianas; ahora, en cambio, ellas se componian de quienes no tardarian en convertirse en simpatizantes peronistas, hablaban el lenguaje de los derechos sociales y trataban, al mismo tiempo, de defender su compatibilidad con los valores cristianos, de ahí que las mismas organizaciones juveniles que en 1945 aclamaron a Perón, poco después se ocuparon de defender la enseñanza religiosa obligatoria, sancionada por el congreso en 1947, sobre la base del decreto anterior del gobierno militar. En especial, hemos destacado el rol jugado por la JOC, el más lúcido ensayo de fundar un movimiento socialcristiano alejado de las jerarquias eclesiásticas más conservadoras. El movimiento fundado por el sacerdote belga tuvo amplia proyección internacional en Europa y América Latina, y rehuyó sistemáticamente las acusaciones de amarillismo. No obstante, el solo hecho de tener que salir a disputar el terreno frente a las izquierdas sometió al catolicismo social a una desgastante lucha de la que no siempre salió airoso.

El fin de la Segunda Guerra Mundial modificó sin embargo el tablero.

20. "Una prolongada entrevista mantuvo con el Presidente el canónigo Cardijn", El Pueblo, 28 de octubre de 1948, p. 1. 
El catolicismo se alineó con Occidente en plena guerra fría y adoptó los valores democráticos; en América Latina y otros escenarios poscoloniales, a su vez, se aproximó incluso a las "nuevas izquierdas" de los años 60 y 70. Pero a partir de 1989 el colapso de la Unión Soviética instaló un nuevo escenario, que no pudo sino impactar hondamente en el catolicismo contemporáneo. Juan Pablo II celebró con una importante encíclica el centenario de la Rerum Novarum, en 1991, con la expectativa de que la doctrina social de la Iglesia ganara amplia legitimidad en un momento en que el capitalismo se quedaba casi sin antagonistas. Si todavia hasta la década de 1980 el catolicismo había debido lidiar con el fantasma del comunismo, la caída del muro fue una gran oportunidad para el catolicismo. No en vano el actual papa Francisco se plegaria tan efusivamente a celebrar el 25 aniversario de la caída de la Unión Soviética en 2014. Las consecuencias de la caída del muro, sumadas a la crisis del Estado de Bienestar, los fuertes avances del neoliberalismo desde la década de 1970 y las sucesivas crisis financieras, junto con los problemas sociales, humanitarios y ecológicos en economías cada vez más desreguladas, le presentaron al Vaticano una oportunidad que Francisco buscó aprovechar desde que accedió al pontificado con la intención de remozar el catolicismo social y ofrecerlo en una versión más apropiada para el siglo XXI, tal como se vio a través de su encíclica Laudato sii, que recogió argumentos provenientes de la tradición del viejo catolicismo social, remozados a su vez con los debates introducidos por los movimientos tercermundistas, ecologistas y humanistas de los años 60 en adelante.

Se trata de la misma versatilidad que el catolicismo social argentino había aprendido, a lo largo del siglo XX. Si bien a veces a desgano, esa plasticidad era fruto de una transformación sustantiva y fundamental que excedia, por cierto, al propio contexto argentino: en 1891, la cuestión social que tanto preocupaba a las elites se podía definir, ante todo, como una cuestión obrera, en tanto que lo que estaba en juego eran las condiciones de trabajo a la luz del proceso de industrialización. A lo largo del siglo XX, en cambio, el contenido de las reivindicaciones sociales se fue transformando en un sentido sustancial a tal punto que hoy en día no se habla de la cuestión social en tanto que cuestión pura y exclusivamente obrera sino, en un sentido más amplio, como una cuestión de dignidad humana, sin distinciones de clase, de género o de cualquier otro tipo. Esta resignificación de la cuestión social forma parte de una historia compleja e inacabada, que debe ser escrita plenamente para entender las transformaciones en el catolicismo social desde León XIII hasta Francisco; este artículo solamente intentó mostrar la historicidad de la cuestión social y las transformaciones sufridas en la primera mitad 
del siglo XX en la Argentina, una base que puede ser útil para pensar las metamorfosis ocurridas de ahí en adelante.

\section{Bibliografía}

Auza, Néstor Tomás (1987), Aciertos y fracasos sociales del catolicismo argentino, Buenos Aires: Docencia-Don Bosco-Guadalupe.

Caimari, Lila (2005), "Sobre el criollismo católico. Notas para leer a Leonardo Castellani", Prismas. Revista de historia intelectual, 9.

Castro, Martín (2013), "Contra la apatía de los buenos: católicos y política partidaria en la ciudad de Buenos Aires, 1902-1918”, Boletin PolHis, 11, primer semestre.

De Andrea, Miguel (1945), "Europa, la Argentina, la familia”, Obras completas, Buenos Aires: Difusión, vol. 3.

Lida, Miranda (2013), Monseñor Miguel De Andrea. Obispo y hombre de mundo, Buenos Aires: Edhasa.

- (2015), Historia del catolicismo argentino. Entre el siglo XIX y el XX, Buenos Aires: Siglo XXI.

- (2016), "Círculos de Obreros, nación, masculinidad y catolicismo de masas en Buenos Aires (1892-década de 1930)", Anuario de la Escuela de Historia de la Universidad Nacional de Rosario, 28.

Martín, María del Carmen Pía (2012), Iglesia Católica, cuestión social y ciudadania. Rosario-Buenos Aires, 1892-1930, tesis de doctorado, UNR.

Rapalo, María Ester (2012), Patrones y obreros. La ofensiva de la clase propietaria, 1918-1930, Buenos Aires: Siglo XXI.

Roselli, Silvana (2009), "Catolicismo social en el obispado de Pablo Padilla y Bárcena. Tucumán, 1897-1921”, Segundas Jornadas de Historia Social, La Falda.

Vidal, Gardenia (2006), "Ciudadanía y asociacionismo. Los Círculos de Obreros en la ciudad de Córdoba, 1897-1912", Revista Escuela de Historia, Universidad Nacional de Salta, 5.

Zimmermann, Eduardo (1995), Los liberales reformistas. La cuestión social en la Argentina, 1890-1916, Buenos Aires: Sudamericana-Universidad de San Andrés. 